\title{
Elemental Analysis of Particles PM2.5 by SEM-EDS
}

\author{
R. Ramirez-Leal ${ }^{1}$, M. Valle-Martinez ${ }^{1}$ and M. Cruz-Campas ${ }^{1}$ \\ 1. State University of Sonora, Ley Federal del Trabajo Final s/n, Col. Apolo Hermosillo, Sonora, \\ Mexico
}

Particles with dimensions below $2.5 \mu \mathrm{m}$ (PM2.5 fine particulates) are especially under consideration due to its relationship with respiratory illnesses, cardiovascular conditions and an increase of mortality indexes(1)

The knowledge of the atmospheric pollutants, is essential to assess their impact on environment and on human health. Because of its small diameter, PM2.5 can be deposited in lung and due to its large surface area, toxins including polycyclic aromatic hydrocarbons (PAH) and heavy metals are absorbed onto the surface. Therefore, fine airborne particles (PM2.5) are regarded to be more toxic than coarse particles.

Samples were analyzed using a scanning electron microscope (SEM) JEOL JSM-5800LV coupled with an energy dispersed spectrometry (EDS) microanalysis EDAX DX4 was used, with a lower detection limit per element of less than $0.1 \%$, to perform single particle analysis and also to determine the PM size. (2)

For analysis by Scanning Electron Microscopy (SEM), samples were taken by cutting circular on the filter paper with an area of $1 \mathrm{~cm}^{2}$, then the samples were supported with double-sided tape of copper in a sample holder of aluminum.

This work is based on samplings PM2.5 collected in atmospheric monitoring station area Northeast of the Air Quality Improvement Municipal Program for the City of Hermosillo, Sonora, Mexico.

The aim of this work is elemental analysis of particles present in samples of PM2.5 as part of an air quality study by SEM-EDS

The City of Hermosillo is located between latitude $20^{\circ} 01^{\prime} 00$ "and $20^{\circ} 08^{\prime} 30^{\prime \prime}$ north latitude and

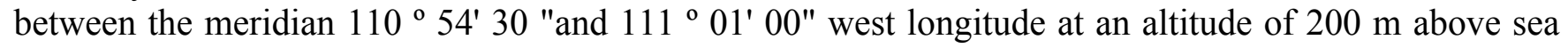
level; is the Sonora state's capital, located to the Center-West of the coastal plain, in northwestern Mexico. (3)

The major chemical elements found by energy dispersive analysis, are maintained in nearly all samples and are $\mathrm{C}(\mathrm{Wt} \%$ 20,80), $\mathrm{Na}(\mathrm{Wt} \%$ 08.76), $\mathrm{Mg}(\mathrm{Wt} \% 01.39), \mathrm{Al}(\mathrm{Wt} \% 03.94), \mathrm{Si}(\mathrm{Wt} \% 22.27), \mathrm{Ca}(\mathrm{Wt} \%$ 02.67), $\mathrm{K}(\mathrm{Wt} \%$ 01.40), $\mathrm{O}(\mathrm{Wt} \%$ 13.27) and $\mathrm{Ba}(\mathrm{Wt} \%$ 09.82). Some particles are some other chemical elements such as lead, iron and combinations of oxygen, iron and combinations with: manganese and chromium, zinc, particles with $\mathrm{S}$ and $\mathrm{Na}$, silver, titanium, sodium and chlorine, $\mathrm{V}$ and $\mathrm{Ce}, \mathrm{Cr}, \mathrm{Fe}, \mathrm{Ni}$

A wide range of particle sizes as shown in electron microscopy images found. The elements normally found using energy dispersive were: $\mathrm{C}, \mathrm{Na}, \mathrm{Mg}, \mathrm{Al}, \mathrm{Si}, \mathrm{Ca}, \mathrm{K}, \mathrm{O}$ and $\mathrm{Fe}$, characteristic of clays, sand and filter. In smaller proportion it has some particles with the following elements: $\mathrm{V}, \mathrm{Pb}, \mathrm{Sn}, \mathrm{Mn}, \mathrm{Zn}$, $\mathrm{Ni}, \mathrm{Cr}, \mathrm{S}, \mathrm{Ti}, \mathrm{Ag}, \mathrm{La}, \mathrm{Ce}, \mathrm{Cl}$, and $\mathrm{Cu}$, combinations of $\mathrm{Na}$ and $\mathrm{S}$ sometimes with $\mathrm{Ca}$. In these analyses it was taken into the filters excess sodium chloride, some particles they presented excessive chlorine or 
sulfur.

References:

[1] Ma. Cristina Castañón Bautista et al. 2015. International Journal of Applied Science and Technology. Vol. 5, No. 2

[2] Yunbo Zhai, Zongmin Fu and Lafang Wang. 2012. Environ Monit Assess 184:6693-6707

[3] R. Ramirez-Leal, Microsc. Microanal. 15 (Suppl. 2) (2009) 1300-1301
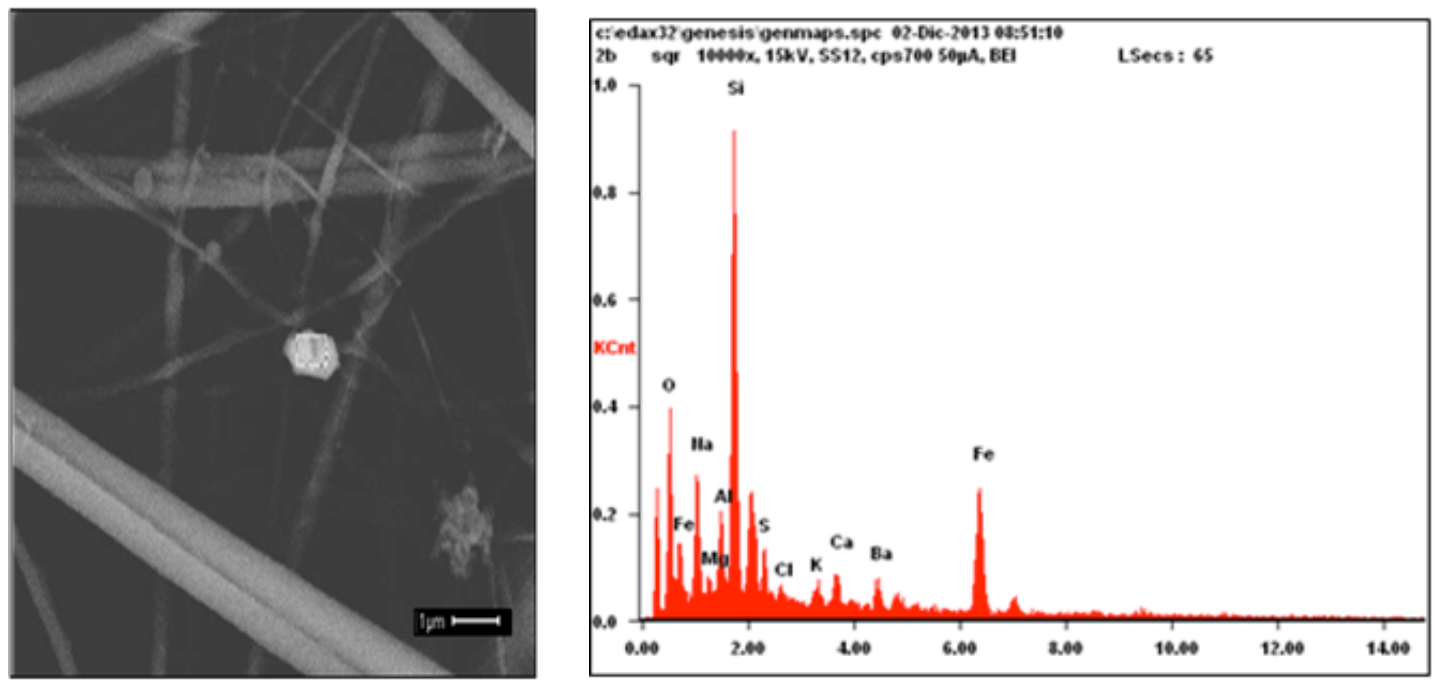

Figure 1. Micrograph of the sample in SEM-EDS to $10000 \mathrm{X}$, BEI and $15 \mathrm{kV}$. 